\title{
Seroprevalence of Ehrlichia canis, Ehrlichia chaffeensis and Ehrlichia ewingii in dogs in North America
}

\author{
Melissa J Beall ${ }^{1 *}$, A Rick Alleman², Ed B Breitschwerdt ${ }^{3}$, Leah A Cohn ${ }^{4}$, C Guillermo Couto ${ }^{5}$, Michael W Dryden ${ }^{6}$, \\ Lynn C Guptill7, Cristina lazbik ${ }^{5}$, Stephen A Kania ${ }^{8}$, Patty Lathan ${ }^{9}$, Susan E Little ${ }^{10}$, Alma Roy ${ }^{11}$, Katherine A Sayler ${ }^{2}$, \\ Brett A Stillman', Elizabeth G Welles ${ }^{12}$, Wendy Wolfson ${ }^{11}$ and Michael J Yabsley ${ }^{13}$
}

\begin{abstract}
Background: This study evaluated the exposure of dogs to three different Ehrlichia spp. in the south and central regions of the United States where vector-borne disease prevalence has been previously difficult to ascertain, particularly beyond the metropolitan areas.

Methods: Dog blood samples $(n=8,662)$ were submitted from 14 veterinary colleges, 6 private veterinary practices and 4 diagnostic laboratories across this region. Samples were tested for E. canis, E. chaffeensis and E. ewingii specific antibodies using peptide microtiter ELISAs.

Results: Overall, E. canis, E. chaffeensis and E. ewingii seroprevalence was $0.8 \%, 2.8 \%$, and $5.1 \%$, respectively. The highest E. canis seroprevalence (2.3\%) was found in a region encompassing Arkansas, Louisiana, Oklahoma, Tennessee and Texas. E. chaffeensis seroreactivity was 6.6\% in the central region (Arkansas, Kansas, Missouri, and Oklahoma) and $4.6 \%$ in the southeast region (Georgia, Maryland, North Carolina, South Carolina, Tennessee and Virginia). Seroreactivity to E. ewingii was also highest in the central region (14.6\%) followed by the southeast region (5.9\%). The geospatial pattern derived from E. chaffeensis and E. ewingii seropositive samples was similar to previous reports based on E. chaffeensis seroreactivity in white-tailed deer and the distribution of human monocytic ehrlichiosis (HME) cases reported by the CDC.

Conclusions: The results of this study provide the first large scale regional documentation of exposure to E. canis, E. chaffeensis and E. ewingii in pet dogs, highlighting regional differences in seroprevalence and providing the basis for heightened awareness of these emerging vector-borne pathogens by veterinarians and public health agencies.
\end{abstract}

Keywords: Ehrlichia, E. canis, E. chaffeensis, E. ewingii, dog, tick, prevalence

\section{Background}

Dogs are susceptible to infection with multiple Ehrlichia spp., including E. chaffeensis and E. ewingii, which are predominantly transmitted by Amblyomma americanum (lone star tick), and to E. canis, whose primary vector is considered to be Rhipicephalus sanguineus (brown dog tick) [1-4]. Amblyomma americanum is commonly found on dogs and people in the southeastern and southcentral United States; indeed, human monocytic ehrlichiosis caused by E. chaffeensis is the most frequently diagnosed

\footnotetext{
* Correspondence: melissa-beall@idexx.com

'IDEXX Laboratories, Inc., Westbrook, ME, USA

Full list of author information is available at the end of the article
}

tick-borne disease in the southern U.S. [5,6]. The number of human monocytic ehrlichiosis cases reported annually has also risen steadily from 200 patients in the year 2000 to over 900 patients in 2009 [7,8]. Infections with E. ewingii are also well documented in both dogs and humans in the southeastern and southcentral U.S. [4,9-12]. The geographic range of $A$. americanum has expanded dramatically in recent decades to include many areas of the Midwest and Northeast, resulting in a concomitant increase in the regions at risk for autochthonous transmission of E. chaffeensis and E. ewingii to dogs and people $[6,13]$. Investigative field surveys have implicated other tick species, including Dermacentor variabilis

\section{Biomed Central}

(c) 2012 Beall et al; licensee BioMed Central Ltd. This is an Open Access article distributed under the terms of the Creative Commons Attribution License (http://creativecommons.org/licenses/by/2.0), which permits unrestricted use, distribution, and reproduction in any medium, provided the original work is properly cited. 
(American dog tick) and $R$. sanguineus, which have been implicated as secondary vectors of $E$. chaffeensis and/or E. ewingii [14-16], but the relative importance of these ticks in maintaining a sustained cycle of infection in nature remains to be determined.

Rhipicephalus sanguineus ticks, the vectors for E. canis, are also common in the warmer climates of the southern U.S., due in part to their tropical or Mediterranean origin and general intolerance of cold temperatures $[17,18]$. Brown dog ticks are thought to have been introduced to the Americas, most likely on tick infested dogs from Europe. Because this tick can survive inside dwellings wherever dogs are present, $R$. sanguineus is now considered to be endemic throughout the U.S. with higher prevalence in particular geographic regions [19-21]. Brown dog ticks are known or strongly suspected to transmit a number of other pathogens to dogs in North America, including Bartonella vinsonii subsp. berkhoffii, Rickettsia rickettsii, Babesia canis, Hepatozoon canis, and Anaplasma platys [17,22].

Diagnosis of an ehrlichial infection can be performed using visual, serologic or molecular methods. Erhlichia spp. replicate inside a membrane bound vacuole (i.e., morula) that can sometimes be observed by light microscopic examination of stained blood smears inside either monocytes (E. canis and E. chaffeensis) or granulocytes (E. ewingii). Detection of antibodies can be performed by immunofluorescent assay (IFA) or enzyme linked immunosorbant assays (ELISA) but cross-reactivity between antibodies to Ehrlichia species is possible [23]. Polymerase chain reaction (PCR) is the most common molecular method used to diagnose an Ehrlichia spp. infection, particularly in dogs with acute illness where the onset of clinical signs may precede a measurable antibody response.

Serologic surveys of dogs for exposure to tick-borne pathogens have been used to identify areas where both people and dogs are at risk of acquiring infection [24-28]. However, prospective surveys involving dogs have often been limited to a small geographic region, such as a portion of a single state [29-31]. Reports of large scale retrospective analyses may be skewed to areas with higher human population density and thus higher pet dog density. However, these regions may not represent regions with the highest tick exposure. For example, in a recent publication describing exposure to common tick-borne pathogens in nearly one million dogs from the U.S. [25], only $6.4 \%$ of samples came from the states of Kansas, Oklahoma, Missouri, Arkansas, Louisiana, and Mississippi, where very dense populations of $A$. americanum ticks are found. In addition, the majority of results reported were from urban areas within the states. To combat the bias inherent in such surveys and to better document the prevalence of exposure to Ehrlichia spp. in the south and central U.S., samples collected from dogs presenting primarily to regional veterinary colleges were tested for E. canis, E. chaffeensis and E. ewingii specific antibodies. A better understanding of the distribution of exposure to these three ehrlichial agents in dogs will provide insight into areas where people and dogs are at greatest risk of infection.

\section{Methods}

\section{Canine Serum Samples}

A total of 8,662 canine serum samples were collected from 14 veterinary colleges, 4 commercial diagnostic laboratory locations and 6 private veterinary practices. Participating veterinary colleges included Auburn University, University of Florida, University of Georgia, University of Illinois, Kansas State University, Louisiana State University (LSU), Mississippi State University, University of Missouri, North Carolina State University (NCSU), The Ohio State University, Oklahoma State University (OKSU), Purdue University, University of Tennessee, and Texas A\&M University (TAMU). Participating commercial diagnostic laboratories were located in Dallas, TX, Baltimore, MD, Totowa, NJ, and North Grafton, MA. The private practices were located in Arkansas, Missouri, North Carolina and Tennessee. The majority of samples collected from veterinary colleges and from all diagnostic laboratories consisted of serum that remained after performance of requested diagnostic tests unrelated to this study. These samples were chosen randomly, without regard to clinical signs or suspected diagnosis, from among all remaining serum samples from dogs $\geq 6$ months of age. Serum samples collected from dogs involved in shelter medicine programs represented all samples from Texas A\&M and 183/307 serum samples from Louisiana State University. Samples submitted from NCSU included an equal number (250 each) of randomly chosen samples and samples previously submitted to the NCSU Vector-Borne Disease Diagnostic Laboratory (VBDDL) for serological testing. More than half of the serum samples collected from OKSU (360/503) were originally submitted for brucellosis testing. For samples submitted from private veterinary practices, a small additional volume of blood (approximately $2 \mathrm{ml}$ ) was collected with informed owner consent specifically for the purposes of this study at the time of blood collection related to routine veterinary care; sampled dogs were chosen from the general population and not selected based on particular clinical signs. Although most samples were collected between January 2009 and October 2010, 250 samples from the NCSU-VBDDL were collected during the first 6 months of 2006 .

\section{Data collection}

Limited patient information was available for the samples. However, the date of sample collection, the dog's 
actual or approximate age, and the address zip code of the dog's owner, veterinary hospital or shelter was recorded. Neither breed nor gender of dogs was recorded.

\section{Serology}

All serum samples were tested by 3 microtiter plate ELISAs, each one using a species-specific peptide for the detection of antibodies reactive to $E$. canis, E. chaffeensis and $E$. ewingii. Synthetic peptides were derived from the E. ewingii $\mathrm{p} 28$ protein (EESP), the E. canis $\mathrm{p} 16$ protein, and the E. chaffeensis variable-length PCR target (VLPT) protein $[32,33]$. Testing was performed as previously described with minor modifications [32]. Samples were initially screened on each of the 3 microtiter plate ELISAs using an indirect assay protocol and confirmed using the same peptide ELISA but with a peptide-labeled direct assay. Briefly, in the indirect assay, diluted samples (1:100) were incubated in each of the 3 species-specific ELISA peptide-coated wells for 30 minutes, the wells were washed ( $300 \mu \mathrm{L} /$ well with PBS plus detergent), and horseradish peroxidase-labeled anti-canine antibody (1:1000 dilution in a diluent containing non-specific protein and detergent) was added to each well and incubated for 30 minutes. Plates were washed as above, 3,3',5,5' teteramethylbenzidine (TMB) substrate solution $(50 \mu \mathrm{L} /$ well) was added, and optical density was determined at $650 \mathrm{~nm}$; reactive samples were denoted by any absorbance value $>2$ times the negative control value. Reactive samples were confirmed in duplicate by adding $50 \mathrm{ul}$ of the serum sample and $100 \mu \mathrm{L}$ of a species-specific peptide horseradish peroxidase conjugate ( 0.5 to $2.0 \mu \mathrm{g} / \mathrm{mL}$ in diluent) to the microtiter-plate ELISA coated with the species-specific peptide. This was allowed to incubate for $60 \mathrm{~min}$, microtiter wells were then washed 6 times, incubated with TMB substrate $(100 \mu \mathrm{L} /$ well $)$ and read at 650 $\mathrm{nm}$ as described above.

Results for E. canis immunofluorescence assays (IFA) were available for 249 samples from the VBDDL at NCSU. Testing was performed following previously described standard procedures of the VBDDL service [34]. E. canis antigens (NCSU Jake strain) were grown in vitro in DH82 cells by the VBDDL. Seropositive samples were defined as having endpoint titers $\geq 64$ using a dilution scale of 1:16 - 1:8192.

\section{Analysis}

Seroprevalence for each pathogen was determined by county and state using zip code data of the patient, shelter or veterinary practice submitting the sample. At least 50 samples were required from a state in order to calculate seroprevalence as depicted in the maps. Seroprevalence results by county were calculated if at least 5 samples were obtained from a county. Geographic regions for comparison of seroprevalence were determined according to the expected tick population pressure. For seroprevalence of $E$. canis, which is transmitted primarily by $R$. sanguineus, the region with the greatest expected tick pressure was defined to include Alabama, Arkansas, Florida, Georgia, Louisiana, Mississippi, North Carolina, Oklahoma, South Carolina, Tennessee and Texas and this region was compared to all other states. For seroprevalence of E. ewingii and E. chaffeensis, which are transmitted primarily by $A$. americanum, the regions expected to have the greatest $A$. americanum pressure were defined as central (Arkansas, Kansas, Missouri, and Oklahoma), or southeastern (Georgia, Maryland, North Carolina, South Carolina, Tennessee and Virginia), and these two regions were compared to all other states. Comparison of seroprevalence between two geographic regions, as well as comparisons between groups of dogs, was made using the Chi-square test $(P<0.05$ considered significant) while a one-way ANOVA with significance assigned at $P<0.05$ was used for comparisons of 3 or more regions. Rates of HME per million in the population were calculated based upon the reported cases per state for the years 2008-2009 divided by the U.S. census data per state for the same years. Comparison of HME rates to Ehrlichia spp. seroprevalence was performed using a linear regression for those states with at least 50 canine samples and the coefficient of determination $\left(R^{2}\right)$ was calculated. Analyses were performed using GraphPad Prism v.5 (GraphPad Software, La Jolla, CA).

\section{Results}

The 8,662 canine serum samples originated from dogs in 41 states, with more than 600 samples from each of the states of Texas, Florida, Missouri and Georgia (Table 1). Many universities enrolled in the study collected at least 300 samples with the most being submitted by the University of Florida (Table 2). The average age of the dogs sampled was 6.6 years (range $0.5-23$ years). The average age of dogs residing in shelters was younger (3.4 years) than the other dogs sampled (7.0 years) as was the age of dogs tested for brucellosis (3.1 years).

Of the 8,662 samples tested, 618 (7.1\%) were determined to have antibodies to at least one of the three Ehrlichia species. Antibodies to E. canis, E. chaffeensis or E. ewingii were detected in 71 (0.8\%), 240 (2.8\%) and 439 (5.1\%) samples, respectively (Table 1). In 132 samples, antibodies to more than one Ehrlichia species were detected. The majority of these co-exposed dogs had antibodies to both E. ewingii and E. chaffeensis (121/132; 92\%). Seven dogs had antibodies to E. ewingii and E. canis, 3 dogs had antibodies to E. canis and E. chaffeensis and only one dog was found to have antibodies to all three Ehrlichia species. Dogs with antibodies to E. chaffeensis were significantly more likely to have 
Table 1 Distribution of canine samples by state and Ehrlichia spp. seroprevalence relative to reported cases of HME.

\begin{tabular}{|c|c|c|c|c|c|c|}
\hline State & Total Number Samples & Total Ehrlichia (\%) & $\begin{array}{c}\text { E. canis } \\
(\%)\end{array}$ & E. ewingii (\%) & E. chaffeensis (\%) & HME cases/M* \\
\hline Alaska & 2 & 0 & 0 & 0 & 0 & $\mathbf{N}$ \\
\hline Alabama & 337 & $15(4.5)$ & $1(0.3)$ & $12(3.6)$ & $5(1.5)$ & 1.8 \\
\hline Arkansas & 84 & $37(44.0)$ & $3(3.6)$ & $31(36.9)$ & $18(21.4)$ & 21.7 \\
\hline Arizona & 1 & 0 & 0 & 0 & 0 & 0 \\
\hline California & 5 & 0 & 0 & 0 & 0 & 0.04 \\
\hline Colorado & 5 & 0 & 0 & 0 & 0 & N \\
\hline Connecticut & 97 & 0 & 0 & 0 & 0 & 0.3 \\
\hline Delaware & 27 & 0 & 0 & 0 & 0 & 23.3 \\
\hline Florida & 733 & $27(3.7)$ & $4(0.5)$ & $19(2.6)$ & $9(1.2)$ & 0.6 \\
\hline Georgia & 662 & $51(7.7)$ & $1(0.2)$ & $36(5.4)$ & $23(3.5)$ & 1.9 \\
\hline Hawaii & 2 & 0 & 0 & 0 & 0 & $N$ \\
\hline lowa & 14 & 0 & 0 & 0 & 0 & N \\
\hline Illinois & 489 & $17(3.5)$ & 0 & $8(1.6)$ & $9(1.8)$ & 2.4 \\
\hline Indiana & 553 & $4(0.7)$ & 0 & $4(0.7)$ & $3(0.5)$ & 0.3 \\
\hline Kansas & 457 & $35(7.7)$ & $4(0.9)$ & $31(6.8)$ & $5(1.1)$ & 1.1 \\
\hline Kentucky & 16 & $3(18.8)$ & $1(6.3)$ & $3(18.8)$ & 0 & 2.9 \\
\hline Louisiana & 274 & $6(2.2)$ & $4(1.5)$ & $2(0.7)$ & 0 & 0 \\
\hline Massachusetts & 241 & $2(0.8)$ & 0 & $2(0.8)$ & $2(0.8)$ & 2.3 \\
\hline Maryland & 254 & $16(6.3)$ & $2(0.8)$ & $9(3.5)$ & $9(3.5)$ & 8.3 \\
\hline Maine & 13 & 0 & 0 & 0 & 0 & 0.8 \\
\hline Michigan & 9 & 0 & 0 & 0 & 0 & 0.5 \\
\hline Minnesota & 7 & 0 & 0 & 0 & 0 & 2.1 \\
\hline Missouri & 663 & $190(29)$ & $5(0.8)$ & $151(22.8)$ & $85(12.8)$ & 28.4 \\
\hline Mississippi & 151 & $9(6.0)$ & 0 & $9(6.0)$ & $2(1.3)$ & 1.0 \\
\hline Montana & 1 & 0 & 0 & 0 & 0 & $\mathbf{N}$ \\
\hline North Carolina & 403 & $41(10.2)$ & $3(0.7)$ & $21(5.2)$ & $23(5.7)$ & 4.7 \\
\hline Nebraska & 62 & 1 & $1(1.6)$ & 0 & 0 & 1.4 \\
\hline New Hampshire & 28 & 0 & 0 & 0 & 0 & 4.2 \\
\hline New Jersey & 257 & $10(3.9)$ & $1(0.4)$ & $7(2.7)$ & $5(1.9)$ & 9.0 \\
\hline New York & 188 & $3(1.6)$ & 0 & $3(1.6)$ & $1(0.5)$ & 3.7 \\
\hline Ohio & 428 & $5(1.2)$ & $4(0.9)$ & $1(0.2)$ & 0 & 1.0 \\
\hline Oklahoma & 514 & $47(9.1)$ & $9(1.8)$ & $37(7.2)$ & $5(1.0)$ & 33.2 \\
\hline Pennsylvania & 96 & $1(1.0)$ & 0 & $1(1.0)$ & 0 & 0.7 \\
\hline Rhode Island & 24 & 0 & 0 & 0 & 0 & 9.0 \\
\hline South Carolina & 34 & $7(20.6)$ & $3(8.8)$ & $2(5.9)$ & $3(8.8)$ & 0.3 \\
\hline South Dakota & 2 & 0 & 0 & 0 & 0 & 0 \\
\hline Tennessee & 181 & $18(9.9)$ & $5(2.8)$ & $14(7.7)$ & $5(2.8)$ & 10.9 \\
\hline Texas & 893 & $23(2.6)$ & $18(2.0)$ & $5(0.6)$ & $1(0.1)$ & 0.7 \\
\hline Virginia & 385 & $48(12.5)$ & $2(0.5)$ & $31(8.1)$ & $25(6.5)$ & 8.4 \\
\hline Wisconsin & 9 & 0 & 0 & 0 & 0 & 4.0 \\
\hline West Virginia & 30 & 1 & 0 & 0 & $1(3.3)$ & 0.3 \\
\hline Unknown & 31 & 1 & 0 & 0 & 1 & \\
\hline Total & 8662 & $618(7.1)$ & $71(0.8)$ & $439(5.1)$ & $240(2.8)$ & \\
\hline
\end{tabular}

*Average incidence of HME cases per million as reported for 2008 and 2009 by passive surveillance; MMWR June 25, 2010 (2008) and May 13, 2011 (2009) (N not reported)

antibodies to $E$. ewingii than were either dogs seronegative for E. chaffeensis $(P<0.0001)$ or dogs seropositive for $E$. canis $(P=0.0051)$.

At least one seroreactive sample was identified from each of 25 states, and seroreactivity for at least 2 of the 3
Ehrlichia species was found in samples from 22 states (Figure 1). The region expected to have the greatest $R$. sanguineus tick pressure (Alabama, Arkansas, Florida, Georgia, Louisiana, Mississippi, North Carolina, Oklahoma, South Carolina, Tennessee and Texas) did not 
Table 2 Number of canine samples submitted by institution and average patient age.

\begin{tabular}{lcc}
\hline Location & Number of samples tested & Average patient age (yrs) \\
\hline Auburn University & 538 & 7.2 \\
University of Florida & 645 & 8.3 \\
University of Georgia & 514 & 8.0 \\
University of Illinois & 425 & 8.0 \\
Kansas State University & 521 & 7.4 \\
Louisiana State University & 307 & 3.7 \\
Mississippi State University & 182 & 7.0 \\
University of Missouri & 614 & 8.0 \\
North Carolina State University & 500 & 7.1 \\
Oklahoma State University & 503 & 3.1 \\
The Ohio State University & 501 & $\mathrm{NA}$ \\
Purdue University & 609 & 8.2 \\
Texas A\&M University & 381 & 3.1 \\
University of Tennessee & 108 & 6.2 \\
Private Veterinary Clinics (6) & 314 & 6.1 \\
Commercial Laboratories (4) & 2000 & 7.0 \\
\hline
\end{tabular}

(NA = not available)

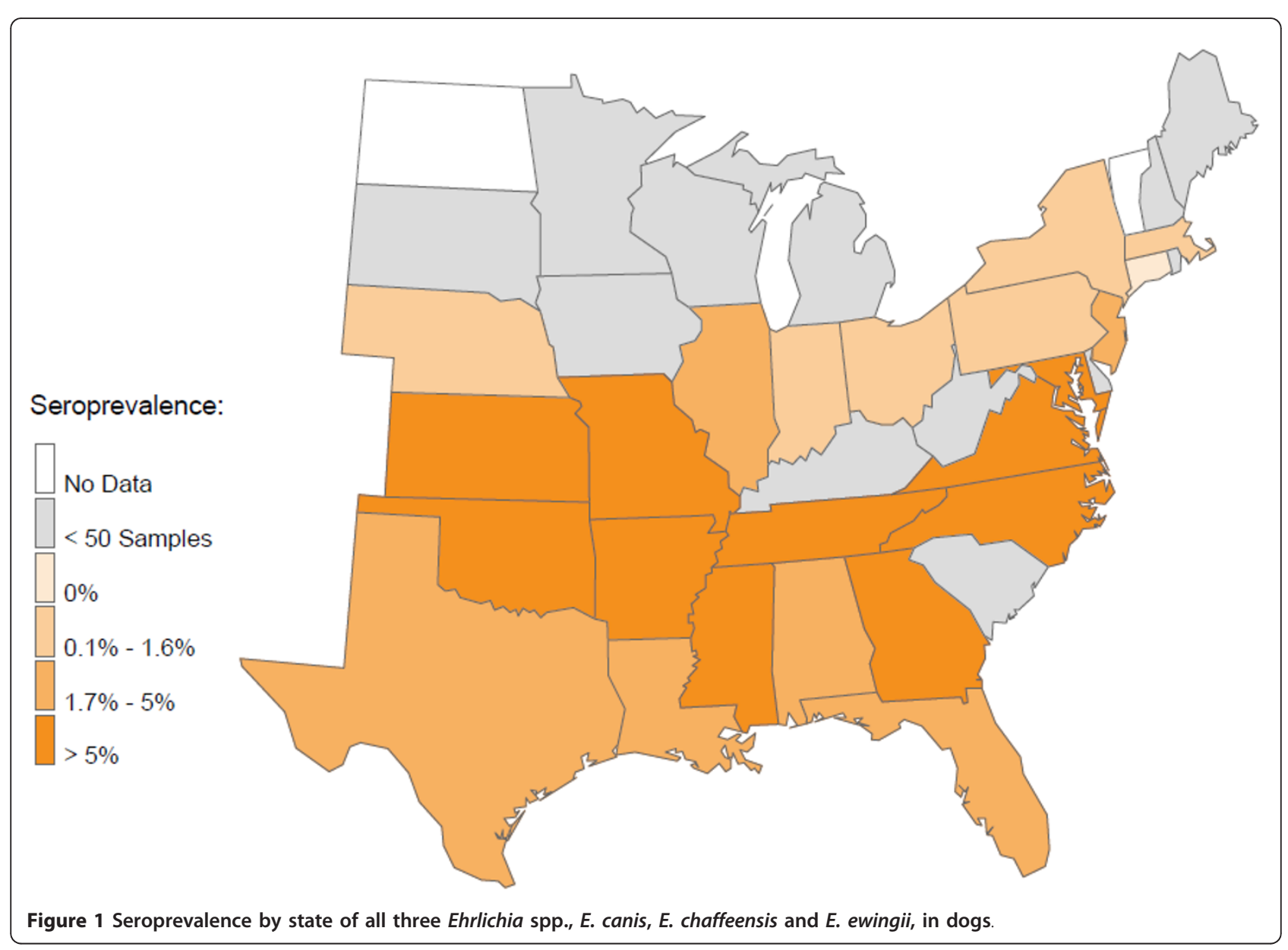


have significantly more $E$. canis seropositive samples (1.2\%) compared to all other states combined $(0.5 \% ; P=$ 0.07) (Figure 2). However, the central portion (Arkansas, Louisiana, Oklahoma, Tennessee, Texas) of this region had significantly more samples seroreactive for $E$. canis than the eastern portion (Alabama, Florida, Georgia, Mississippi, North Carolina, South Carolina) of this region ( $2.0 \%$ vs. $0.5 \%$ respectively; $P=0.0121$ ). Coincident with $A$. americanum distribution, seroreactivity to $E$. chaffeensis (Figures 3, 4) was 6.6\% in the central region (Arkansas, Kansas, Missouri, and Oklahoma) and $4.6 \%$ in the southeast region (Georgia, Maryland, North Carolina, South Carolina, Tennessee and Virginia). Seroprevalence of $E$. chaffeensis in both of these A. americanum indigenous regions was significantly higher than the seroprevalence from all other states combined $(0.7 \% ; P<0.0001)$. However, seroreactivity to $E$. ewingii (14.6\%) was significantly higher in the central region compared with the seroprevalence in the southeastern region $(5.9 \%)$ and when compared to all other states combined $(1.4 \% ; P<$ 0.0001) (Figures 3, 4).

To determine if the seroprevalence of $E$. chaffeensis and $E$. ewingii in dogs might correlate with the number of
HME cases reported per 1,000,000 in the human population, a linear regression was performed on the data. If samples from all states were included, the coefficient of determination $\left(\mathrm{R}^{2}\right)$ was only 0.47 and 0.37 for $E$. ewingii and $E$. chaffeensis, respectively. However, when the samples from dogs with significantly lower average age (those from LSU, OKSU, TAMU) were omitted from the analysis, the coefficient of determination increased to 0.72 and 0.73 for $E$. ewingii and E. chaffeensis, respectively (Figure 5). There was a significant correlation between HME cases reported per million people and seroprevalence of $E$. ewingii and $E$. chaffeensis in dogs $(P<0.0001)$ but not with seroprevalence of $E$. canis in dogs $(P=0.704)$.

E. canis IFA results were compared with that of the Ehrlichia species-specific ELISAs for 249 samples obtained from the NCSU-VBDDL. E. canis IFA identified 5 seropositive samples with titers of greater than or equal to 1:64. The Ehrlichia species ELISAs identified the same 5 samples as seropositive with 3 seroreactive for $E$. canis, one seroreactive for $E$. chaffeensis, and one seropositive for both E. chaffeensis and E. ewingii. The peptide ELISAs detected 20 additional Ehrlichia seroreactive samples within the group that had been negative by $E$. canis IFA.

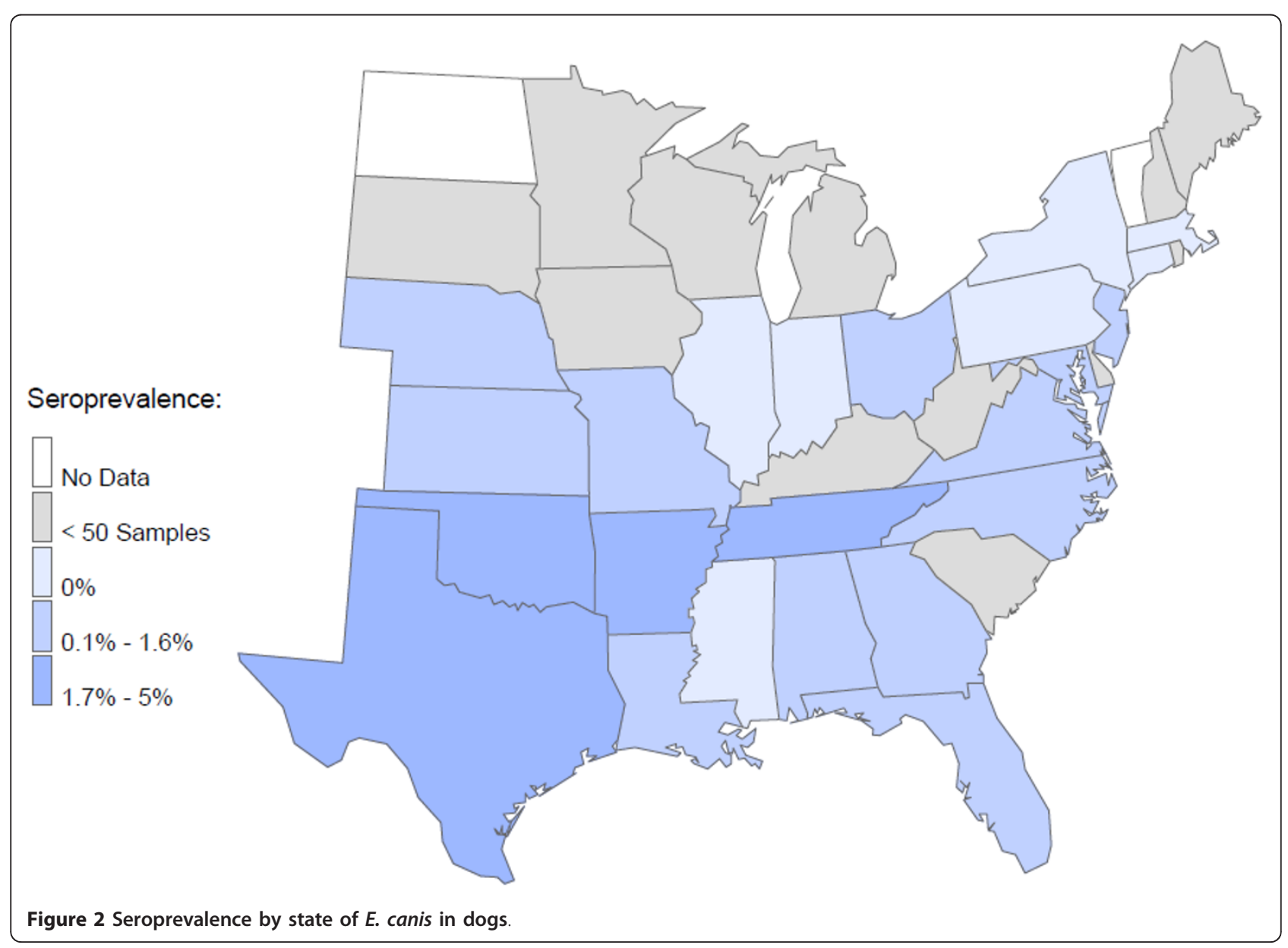




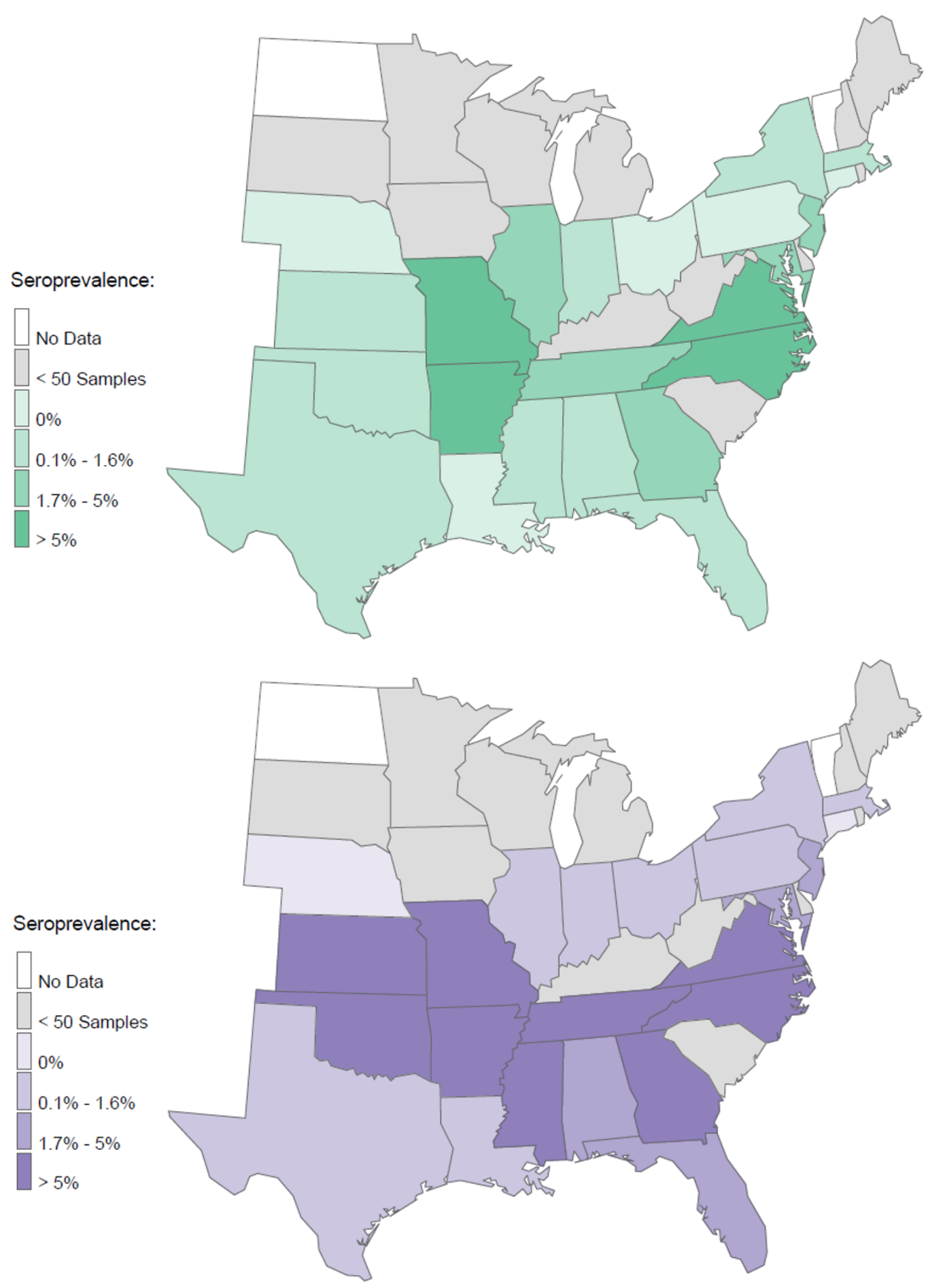

Figure 3 Seroprevalence by state of E. chaffeensis (green) and E. ewingii (purple) in dogs

Of these 20, only 2 were seropositive for E. canis and the remainder had detectable antibodies to E. chaffeensis, $E$. ewingii, or both (Table 3). In this sample set, the E. canis IFA did not detect the $E$. ewingii-only seroreactive samples $(n=7)$ identified by the species-specific peptide ELISA.

\section{Discussion}

This study evaluated the exposure of dogs to three Ehrlichia species, with a particular focus on dogs from the south and central regions of the U.S., using peptide-based species-specific ELISA assays. Based on this study, dogs 


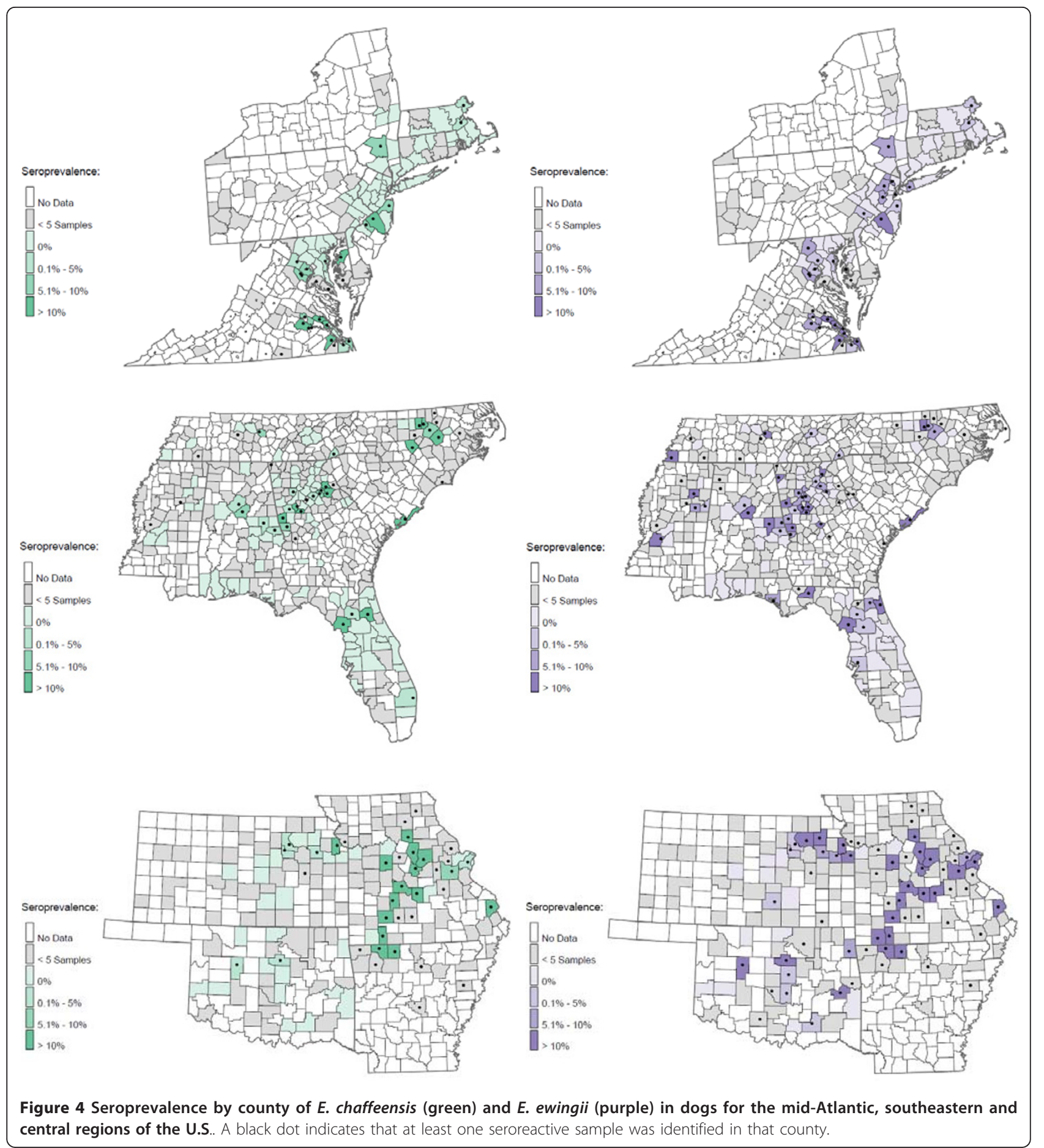

were most commonly exposed to $E$. ewingii with antibodies identified in $5.1 \%$ of all samples tested. Antibodies to E. chaffeensis were identified in $2.8 \%$ of dogs tested. This predominance of $E$. ewingii infection in dogs has been reported previously in studies from Missouri, Arkansas, and Oklahoma $[4,10]$; the present study confirms and extends that finding over a much wider geographic area.
Antibodies to E. ewingii and E. chaffeensis were identified in dogs from 23 and 20 of the 41 states considered, respectively, suggesting a widespread distribution of these agents in the eastern U.S. This pattern parallels the distribution and intensity of A. americanum ticks in nature [35]. Further, it is consistent with data derived by less specific serologic assays using sera from deer and dogs $[25,35,36]$. 


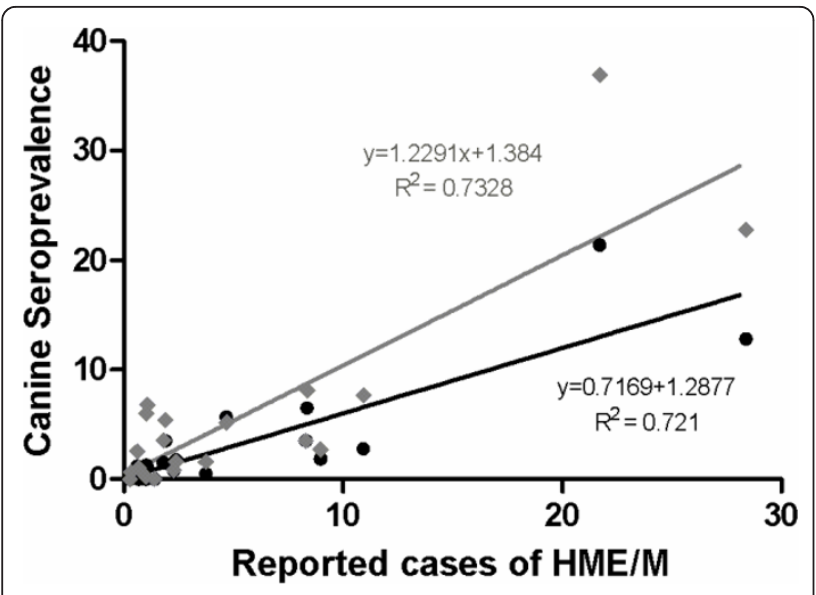

Figure 5 Correlation between the average number of reported cases of $\mathrm{HME} / \mathrm{million}$ people by state and seroprevalence for E. chaffeensis (grey) and E. ewingii (black) in dogs by state. Analysis excluded HME rates and canine seroprevalence from those states where the veterinary institutions had a biased collection of samples from young dogs within the population.

The geographic distribution of E. chaffeensis and E. ewingii seroreactive dogs in the present study is also largely consistent with reports of HME or E. ewingii infections in people (see Table 1). However, the correlation with HME was not identified unless the institutions with a biased selection of young dogs in the population (shelter and kennel/breeder dogs) were excluded from the analysis suggesting that canine exposure may be influenced by the time spent in an endemic environment. A review of individual states revealed some instances where the E. chaffeensis and E. ewingii seroprevalence in dogs exceeded the reported number of HME cases in people. For instance, E. chaffeensis and E. ewingii were identified in approximately the same proportion of dogs tested from Kansas $(1.1 \%$; $6.8 \%)$ and Mississippi $(1.3 \%$; $6.0 \%)$ as from Tennessee $(2.8 \% ; 7.7 \%)$ but no cases of HME were reported from Kansas or Mississippi in 2008 whereas 64 HME cases were reported in people from Tennessee in that year [37]. Results from 2009 show an increase in the number of HME cases in Kansas and

Table 3 Comparison of serologic results using E.canis IFA and the three Ehrlichia species ELISAs

\begin{tabular}{rcccc}
\hline Ehrlichia species by ELISA: & \multicolumn{5}{c}{ E. canis } & IFA/Ehrlichia species ELISAs \\
\cline { 2 - 5 } E. canis & 0 & 3 & 2 & \\
E. ewingii & 0 & 0 & 7 & \\
E. chaffeensis & 0 & 1 & 6 & \\
E. ewingii + E. chaffeensis & 0 & 1 & 5 & \\
\hline Total & $\mathbf{0}$ & $\mathbf{5}$ & $\mathbf{2 0}$ & $\mathbf{2 2 4}$
\end{tabular}

A total of 249 serum samples from the VBDDL at NCSU had previously been tested by $E$. canis IFA. Titers of 1:64 and greater were considered positive.
Mississippi, with each reporting 6 clinical cases, while 73 were reported from Tennessee [7]. Disease reporting often varies from year to year, and underreporting of HME is thought to commonly occur [5]. Alternatively, infection with other Ehrlichia spp. may be responsible for the high number of HME patients reported from regions with low canine seroprevalence as novel Ehrlichia spp. continue to be described [38-40].

Interestingly, $121(1.4 \%)$ dogs in the present study had antibodies to both E. ewingii and E. chaffeensis, suggesting some degree of simultaneous or sequential infection with these two agents, both of which are transmitted primarily by $A$. americanum ticks. Co-infection in dogs with multiple Ehrlichia spp. has been reported from Missouri and North Carolina, based upon molecular methods $[10,34]$. Human co-infection with E. chaffeensis and E. ewingii has not been reported, but the findings from the present study, the shared vector tick, and the inability to distinguish infections with these two agents by less specific serologic techniques, such as IFA, suggests coinfection should be considered in people, particularly when more severe disease is evident. Experimental infection with multiple rickettsial agents in dogs has been shown to lead to more severe disease than infection with a single pathogen [41].

E. canis is a well recognized tick-borne pathogen of dogs known to cause monocytic ehrlichiosis. In this study exposure to E. canis was highest in the region of Texas, Louisiana, Arkansas and Oklahoma, which is consistent with the density of the primary tick vector, $R$. sanguineus. However, the overall seroprevalence of E. canis was much lower compared to the seroprevalence of E. chaffeensis and E. ewingii, which may be consistent with the increase in $A$. americanum numbers and expanding geographic distribution of this tick species [5]. Additionally, previous serosurveys which have utilized methods like $E$. canis IFA or the SNAP ${ }^{\circledR} 3 \mathrm{Dx}^{\circledR}$ or $\mathrm{SNAP}^{\circledR} 4 \mathrm{Dx}^{\circledR}$ test kits to measure E. canis seroprevalence may have detected ehrlichial antibodies other than those specific for $E$. canis resulting in an overestimate of $E$. canis exposure [23,42]. This differs from the present study which utilized a peptide that is specific for $E$. canis and does not detect antibodies to $E$. chaffeensis or E. ewingii [32]. Finally, the advent of more efficacious and long-acting acaracides could be having an impact on E. canis exposure rates in dogs due to the resulting suppression of the natural maintenance cycle for $E$. canis. Both the greater host specificity of $R$. sanguineus ticks relative to $A$. americanum and the lack of wildlife reservoir for $E$. canis favor a suppression of the natural maintenance cycle for $E$. canis relative to $E$. chaffeensis and $E$. ewingii. No such suppression of $A$. americanum maintenance cycles in deer or other wildlife inhabiting natural environments would be expected to be ongoing currently. 
In addition to the results of this study, results from previous experimental infection studies with $E$. chaffeensis and E. ewingii [32] as well as regional field studies [4] have demonstrated the sensitivity and specificity of these peptide reagents for antibody detection in infected canine samples. To further evaluate the performance, a limited number of samples were used to compare the results of the three Ehrlichia ELISAs with E. canis IFA as performed by the NCSU VBDDL. When compared to E. canis IFA, 20/249 samples (8\%) were reactive on the species-specific ELISAs that did not demonstrate reactivity by IFA testing. Results of a previous study demonstrated that up to $8 \%$ of samples with reactivity to Ehrlichia species peptide reagents on SNAP 3Dx (p30/ p30-1) may test negative (titers $<1: 64$ ) on E. canis IFA [23]. The identification of samples having antibodies to E. chaffeensis and/or E. ewingii by ELISA but not confirmed positive by $E$. canis IFA may reflect the variability of cross-reactive antibodies between these Ehrlichia species. Differences in assay format between ELISA and IFA, such as testing a less dilute serum sample and the use of highly concentrated immunodominant epitopes on the ELISA, may account for some of the observed differences. More studies are needed to determine the degree with which cross-reacting antibodies in dogs exposed to E. chaffeensis and E. ewingii will react with E. canis IFA, the primary Ehrlichia species used as antigen in IFA testing by veterinary diagnostic laboratories.

\section{Conclusions}

In this study, we documented that dogs in the central and south central U.S. are more commonly exposed to E. ewingii than other ehrlichial species, and are more commonly exposed to E. chaffeensis than to E. canis. In the case of $E$. chaffeensis and $E$. ewingii, the lone star tick transmits these infectious agents to both dogs and people. The dog has been described as a sentinel for vector-borne infections like Lyme Disease and Rocky Mountain Spotted Fever [29,43-45]. The results of this study provide preliminary evidence that dogs can be tested using Ehrlichia species-specific peptides and serve as a regional or local sentinel to gauge the potential risk for human infection with these tick-transmitted pathogens.

\footnotetext{
Acknowledgements

The authors would like to acknowledge Jill Saucier, Paulette Shields, Jennifer Sinsabaugh, and Brendon Thatcher for their technical assistance with the ELISA testing; Julie Bradley and Barb Hegarty for their technical assistance with IFA testing; Peter Von Kamecke and Jessica Lachtara for assistance with data analysis and mapping; Drs. Walter Hoffmann and Karen Snowden for submitting samples from the University of Illinois and Texas A\&M University, respectively; Drs. Blaine Andrews, Scott Little, Ellen Ratcliff, Jim Russell, Mark Thompson, and Kameron Worley for submitting canine samples from private practice.

This study was funded by IDEXX Laboratories, Inc.
}

\section{Author details}

'IDEXX Laboratories, Inc., Westbrook, ME, USA. ${ }^{2}$ University of Florida, College of Veterinary Medicine, Gainesville, FL, USA. ${ }^{3}$ North Carolina State University, College of Veterinary Medicine, Raleigh, NC, USA. ${ }^{4}$ University of Missouri, College of Veterinary Medicine, Columbia, MO, USA. ${ }^{5}$ The Ohio State University, College of Veterinary Medicine, Columbus, OH, USA. ${ }^{6}$ Kansas State University, College of Veterinary Medicine, Manhattan, KS, USA. ${ }^{7}$ Purdue University, College of Veterinary Medicine, West Lafayette, IN, USA. ${ }^{8}$ University of Tennessee, College of Veterinary Medicine, Knoxville, TN, USA. ${ }^{9}$ Mississippi State University, College of Veterinary Medicine, Mississippi State, MS, USA. ${ }^{10}$ Oklahoma State University, College of Veterinary Medicine, Stillwater, OK, USA. " 'Louisiana State University, College of Veterinary Medicine, Baton Rouge, LA, USA. ${ }^{12}$ Auburn University, College of Veterinary Medicine, Auburn, AL, USA. ${ }^{13}$ University of Georgia, College of Veterinary Medicine, Athens, GA, USA

\section{Authors' contributions}

MJB, SEL and LAC were primarily responsible for the first draft of the manuscript. All authors critically reviewed and approved the final manuscript.

\section{Competing interests}

MJB, and BS are employees of IDEXX Laboratories, Inc. EBB, LAC, MAD, SEL, and MJY have received funding from IDEXX Laboratories, Inc. for education, research or consulting.

Received: 26 September 2011 Accepted: 8 February 2012 Published: 8 February 2012

\section{References}

1. Anziani OS, Ewing SA, Barker RW: Experimental transmission of a granulocytic form of the tribe Ehrlichieae by Dermacentor variabilis and Amblyomma americanum to dogs. Am J Vet Res 1990, 51:929-931.

2. Ewing SA, Dawson JE, Kocan AA, Barker RW, Warner CK, Panciera RJ, Fox JC, Kocan KM, Blouin EF: Experimental transmission of Ehrlichia chaffeensis (Rickettsiales: Ehrlichieae) among white-tailed deer by Amblyomma americanum (Acari: Ixodidae). J Med Entomol 1995, 32:368-374.

3. Groves MG, Dennis GL, Amyx HL, Huxsoll DL: Transmission of Ehrlichia canis to dogs by ticks (Rhipicephalus sanguineus). Am J Vet Res 1975, 36:937-940.

4. Little SE, O'Connor TP, Hempstead J, Saucier J, Reichard MV, Meinkoth K, Meinkoth JH, Andrews B, Ullom S, Ewing SA, Chandrashekar R: Ehrlichia ewingii infection and exposure rates in dogs from the southcentral United States. Vet Parasitol 2010, 172:355-360.

5. Paddock CD, Childs JE: Ehrlichia chaffeensis: a prototypical emerging pathogen. Clin Microbiol Rev 2003, 16:37-64.

6. Salinas $L$, Greenfield RA, Little SE, Voskuhl GW: Tickborne infections in the southern United States. Am J Med Sci 2010, 340:194-201.

7. CDC: Summary of notifiable diseases: United States, 2009. MMWR Morb Mortal Wkly Rep 2011, 58:1-100.

8. CDC: Summary of notifiable diseases: United States, 2000. MMWR Morb Mortal Wkly Rep 2002, 49:1-128.

9. Buller RS, Arens $M$, Hmiel SP, Paddock CD, Sumner JW, Rikhisa $Y$, Unver $A$, Gaudreault-Keener M, Manian FA, Liddell AM, Schmulewitz N, Storch GA: Ehrlichia ewingii, a newly recognized agent of human ehrlichiosis. N Engl J Med 1999, 341:148-155.

10. Liddell AM, Stockham SL, Scott MA, Sumner JW, Paddock CD, GaudreaultKeener M, Arens MQ, Storch GA: Predominance of Ehrlichia ewingii in Missouri dogs. J Clin Microbiol 2003, 41:4617-4622.

11. Masters EJ, Storch GA, Sumner JW: Ehrlichia ewingii in an immunocompetent adult. Mo Med 2009, 106:301-303.

12. Paddock CD, Folk SM, Shore GM, Machado LJ, Huycke MM, Slater LN, Liddell AM, Buller RS, Storch GA, Monson TP, Rimland D, Sumner JW, Singleton J, Bloch KC, Tang YW, Standaert SM, Childs JE: Infections with Ehrlichia chaffeensis and Ehrlichia ewingii in persons coinfected with human immunodeficiency virus. Clin Infect Dis 2001, 33:1586-1594.

13. Paddock CD, Yabsley MJ: Ecological havoc, the rise of white-tailed deer, and the emergence of Amblyomma americanum-associated zoonoses in the United States. Curr Top Microbiol Immunol 2007, 315:289-324. 
14. Ndip LM, Ndip RN, Esemu SN, Walker DH, McBride JW: Predominance of Ehrlichia chaffeensis in Rhipicephalus sanguineus ticks from kennelconfined dogs in Limbe, Cameroon. Exp Appl Acarol 2010, 50:163-168.

15. Ndip LM, Ndip RN, Ndive VE, Awuh JA, Walker DH, McBride JW: Ehrlichia species in Rhipicephalus sanguineus ticks in Cameroon. Vector Borne Zoonotic Dis 2007, 7:221-227.

16. Steiert JG, Gilfoy F: Infection rates of Amblyomma americanum and Dermacentor variabilis by Ehrlichia chaffeensis and Ehrlichia ewingii in southwest Missouri. Vector Borne Zoonotic Dis 2002, 2:53-60.

17. Dantas-Torres F: The brown dog tick, Rhipicephalus sanguineus (Latreille, 1806) (Acari: Ixodidae): from taxonomy to control. Vet Parasitol 2008, 152:173-185.

18. Dantas-Torres F: Biology and ecology of the brown dog tick, Rhipicephalus sanguineus. Parasit Vectors 2010, 3:26.

19. Guglielmone AA, Estrada-Pena A, Keirans JE, Robbins RG: Ticks (Acari: Ixodidae) of the neotropical zoogeographical region. International Consortium on Ticks and Tick-borne Diseases; Houten, Holanda 2003.

20. Walker JB, Keirans JE, Horak IG: The Genus Rhipicephalus (Acari, Ixodidae): A Guide to the Brown Ticks of the World Cambridge: Cambridge University Press; 2000.

21. Approximate Distribution of the Brown Dog Tick. [http://www.cdc.gov/ ticks/maps/brown_dog_tick.html].

22. Pappalardo BL, Correa MT, York CC, Peat CY, Breitschwerdt EB: Epidemiologic evaluation of the risk factors associated with exposure and seroreactivity to Bartonella vinsonii in dogs. Am J Vet Res 1997, 58:467-471.

23. Hegarty BC, de Paiva Diniz PP, Bradley JM, Lorentzen L, Breitschwerdt E: Clinical relevance of annual screening using a commercial enzymelinked immunosorbent assay (SNAP 3Dx) for canine ehrlichiosis. J Am Anim Hosp Assoc 2009, 45:118-124.

24. Beugnet F, Marie $\mathrm{J}$ : Emerging arthropod-borne diseases of companion animals in Europe. Vet Parasitol 2009, 163:298-305.

25. Bowman D, Little SE, Lorentzen L, Shields J, Sullivan MP, Carlin EP: Prevalence and geographic distribution of Dirofilaria immitis, Borrelia burgdorferi, Ehrlichia canis, and Anaplasma phagocytophilum in dogs in the United States: results of a national clinic-based serologic survey. Vet Parasitol 2009, 160:138-148.

26. Foley JE, Brown RN, Gabriel MW, Henn J, Drazenovich N, Kasten R, Green SL, Chomel BB: Spatial analysis of the exposure of dogs in rural north-coastal California to vectorborne pathogens. Vet Rec 2007 , 161:653-657.

27. Hinrichsen VL, Whitworth UG, Breitschwerdt EB, Hegarty BC, Mather TN: Assessing the association between the geographic distribution of deer ticks and seropositivity rates to various tick-transmitted disease organisms in dogs. J Am Vet Med Assoc 2001, 218:1092-1097.

28. Yabsley MJ, McKibben J, Macpherson CN, Cattan PF, Cherry NA, Hegarty BC, Breitschwerdt EB, O'Connor T, Chandrashekar R, Paterson T, Perea ML, Ball G, Friesen S, Goedde J, Henderson B, Sylvester W: Prevalence of Ehrlichia canis, Anaplasma platys, Babesia canis vogeli, Hepatozoon canis, Bartonella vinsonii berkhoffii, and Rickettsia spp. in dogs from Grenada. Vet Parasitol 2008, 151:279-285.

29. Duncan AW, Correa MT, Levine JF, Breitschwerdt EB: The dog as a sentinel for human infection: prevalence of Borrelia burgdorferi $\mathrm{C} 6$ antibodies in dogs from southeastern and mid-Atlantic States. Vector Borne Zoonotic Dis 2005, 5:101-109.

30. Hamer SA, Tsao Jl, Walker ED, Mansfield LS, Foster ES, Hickling GJ: Use of tick surveys and serosurveys to evaluate pet dogs as a sentinel species for emerging Lyme disease. Am J Vet Res 2009, 70:49-56.

31. Murphy GL, Ewing SA, Whitworth LC, Fox JC, Kocan AA: A molecular and serologic survey of Ehrlichia canis, E. chaffeensis, and E. ewingii in dogs and ticks from Oklahoma. Vet Parasitol 1998, 79:325-339.

32. O'Connor TP, Saucier JM, Daniluk D, Stillman BA, Krah R, Rikihisa Y, Xiong Q, Yabsley MJ, Adams DS, Diniz PP, Breitschwerdt EB, Gaunt SD,

Chandrashekar R: Evaluation of peptide- and recombinant protein-based assays for detection of anti-Ehrlichia ewingii antibodies in experimentally and naturally infected dogs. Am J Vet Res 2010, 71:1195-1200.

33. Sumner JW, Childs JE, Paddock CD: Molecular cloning and characterization of the Ehrlichia chaffeensis variable-length PCR target: an antigen-expressing gene that exhibits interstrain variation. J Clin Microbiol 1999, 37:1447-1453.
34. Kordick SK, Breitschwerdt EB, Hegarty BC, Southwick KL, Colitz CM, Hancock SI, Bradley JM, Rumbough R, McPherson JT, MacCormack JN: Coinfection with multiple tick-borne pathogens in a Walker Hound kennel in North Carolina. J Clin Microbiol 1999, 37:2631-2638.

35. Childs JE, Paddock CD: The ascendancy of Amblyomma americanum as a vector of pathogens affecting humans in the United States. Annu Rev Entomol 2003, 48:307-337.

36. Yabsley MJ, Wimberly MC, Stallknecht DE, Little SE, Davidson WR: Spatial analysis of the distribution of Ehrlichia chaffeensis, causative agent of human monocytotropic ehrlichiosis, across a multi-state region. Am J Trop Med Hyg 2005, 72:840-850.

37. CDC: Summary of notifiable diseases: United States, 2008. MMWR Morb Mortal Wkly Rep 2010, 57:1-94.

38. Gajadhar AA, Lobanov V, Scandrett WB, Campbell J, Al-Adhami B: A novel Ehrlichia genotype detected in naturally infected cattle in North America. Vet Parasitol 2010, 173:324-329.

39. Loftis AD, Reeves WK, Spurlock JP, Mahan SM, Troughton DR, Dasch GA, Levin ML: Infection of a goat with a tick-transmitted Ehrlichia from Georgia, U.S.A., that is closely related to Ehrlichia ruminantium. J Vector Ecol 2006, 31:213-223.

40. Pritt BS, Sloan LM, Johnson DK, Munderloh UG, Paskewitz SM, McElroy KM McFadden JD, Binnicker MJ, Neitzel DF, Liu G, et al: Emergence of a new pathogenic Ehrlichia species, Wisconsin and Minnesota, 2009. N Engl J Med 2011, 365:422-429.

41. Gaunt S, Beall M, Stillman B, Lorentzen L, Diniz P, Chandrashekar R, Breitschwerdt E: Experimental infection and co-infection of dogs with Anaplasma platys and Ehrlichia canis: hematologic, serologic and molecular findings. Parasit Vectors 2010, 3:33.

42. O'Connor TP, Esty KJ, Hanscom JL, Shields P, Philipp MT: Dogs vaccinated with common Lyme disease vaccines do not respond to IR6, the conserved immunodominant region of the VIsE surface protein of Borrelia burgdorferi. Clin Diagn Lab Immunol 2004, 11:458-462.

43. Nicholson WL, Allen KE, McQuiston JH, Breitschwerdt EB, Little SE: The increasing recognition of rickettsial pathogens in dogs and people. Trends Parasitol 2010, 26:205-212.

44. Paddock CD, Brenner O, Vaid C, Boyd DB, Berg JM, Joseph RJ, Zaki SR, Childs JE: Short report: concurrent Rocky Mountain spotted fever in a dog and its owner. Am J Trop Med Hyg 2002, 66:197-199.

45. Mead P, Goel R, Kugeler K: Canine serology as adjunct to human lyme disease surveillance. Emerg Infect Dis 2011, 17:1710-1712.

doi:10.1186/1756-3305-5-29

Cite this article as: Beall et al:: Seroprevalence of Ehrlichia canis, Ehrlichia chaffeensis and Ehrlichia ewingii in dogs in North America. Parasites \& Vectors 2012 5:29.

\section{Submit your next manuscript to BioMed Central and take full advantage of:}

- Convenient online submission

- Thorough peer review

- No space constraints or color figure charges

- Immediate publication on acceptance

- Inclusion in PubMed, CAS, Scopus and Google Scholar

- Research which is freely available for redistribution

Submit your manuscript at www.biomedcentral.com/submit
C Biomed Central 